\title{
Modeling Impacts of Climate Change on Giant Panda Habitat
}

\author{
Melissa Songer, ${ }^{1}$ Melanie Delion, ${ }^{1}$ Alex Biggs, ${ }^{1}$ and Qiongyu Huang ${ }^{2}$ \\ ${ }^{1}$ Conservation Ecology Center, Smithsonian Conservation Biology Institute, National Zoological Park, Front Royal, VA 22630, USA \\ ${ }^{2}$ Geography Department, University of Maryland, College Park, MD 20742, USA
}

Correspondence should be addressed to Melissa Songer, songerm@si.edu

Received 14 September 2011; Accepted 19 December 2011

Academic Editor: A. E. Lugo

Copyright () 2012 Melissa Songer et al. This is an open access article distributed under the Creative Commons Attribution License, which permits unrestricted use, distribution, and reproduction in any medium, provided the original work is properly cited.

\begin{abstract}
Giant pandas (Ailuropoda melanoleuca) are one of the most widely recognized endangered species globally. Habitat loss and fragmentation are the main threats, and climate change could significantly impact giant panda survival. We integrated giant panda habitat information with general climate models (GCMs) to predict future geographic distribution and fragmentation of giant panda habitat. Results support a major general prediction of climate change-a shift of habitats towards higher elevation and higher latitudes. Our models predict climate change could reduce giant panda habitat by nearly $60 \%$ over 70 years. New areas may become suitable outside the current geographic range but much of these areas is far from the current giant panda range and only $15 \%$ fall within the current protected area system. Long-term survival of giant pandas will require the creation of new protected areas that are likely to support suitable habitat even if the climate changes.
\end{abstract}

\section{Introduction}

Giant pandas (Ailuropoda melanoleuca) are endangered [1] and attract great popular attention, scientific interest, and conservation dollars. The species' historic range encompassed most of southeastern China, northern Myanmar, and northern Vietnam. Climate changes during the late Pleistocene and millennia of agricultural conversion and human settlement have dramatically reduced the geographic distribution of giant pandas and populations are now scattered across six mountain ranges between the Sichuan plain and Tibetan plateau [2-4].

One of the greatest threats to giant panda survival is habitat loss $[2,5,6]$. The species is limited to montane deciduous and coniferous forests with bamboo understories. During the twentieth century, giant panda habitat steadily and rapidly declined $[3,5,7]$. Driving forces of habitat loss are agricultural conversion, and large-scale activities such as road construction, logging, mining, and hydroelectric development. Habitat loss has led to a highly fragmented range; many giant panda populations are small and isolated, resulting in limited gene flow and risks from inbreeding $[2,4,8,9]$.

Climate change may pose a significant threat to giant panda survival. Current climate models estimate a 1.4-5.8 degree Celsius increase in temperature during this century
[10-13]. Past and recent changes in climate have been shown to cause range shifts and contractions in plant and animal distributions [14-21]. Whether a species can survive changes in their environment is dependent on various life history characteristics. Characteristics that make a species more likely to be negatively impacted by disturbance include having a limited geographic range, poor ability to disperse, low rates of reproduction, and highly specialized habitat requirements [14, 22-24]. Giant pandas have a narrow range, do not disperse over large distances, produce one cub every 2-3 years, and depend on bamboo for $99 \%$ of their diet [25]. These traits suggest they will be highly susceptible to climate change. In addition to the limitations resulting from life history characteristics, species' response is also limited by the spatial configuration of habitat in the landscape. Species may have the capacity to shift as vegetation regimes shift; however, distance or other barriers may limit movement. Given the giant panda's restricted and montane geographic range, climate change may significantly reduce and isolate already fragmented giant panda habitats, decrease gene flow, and thereby substantially increase the species' extinction risk.

Extrapolating known suitable climate envelopes into future climate scenarios is one of the best approaches for predicting effects of climate change on species' geographical distributions [26, 27]. Based on the current giant panda 


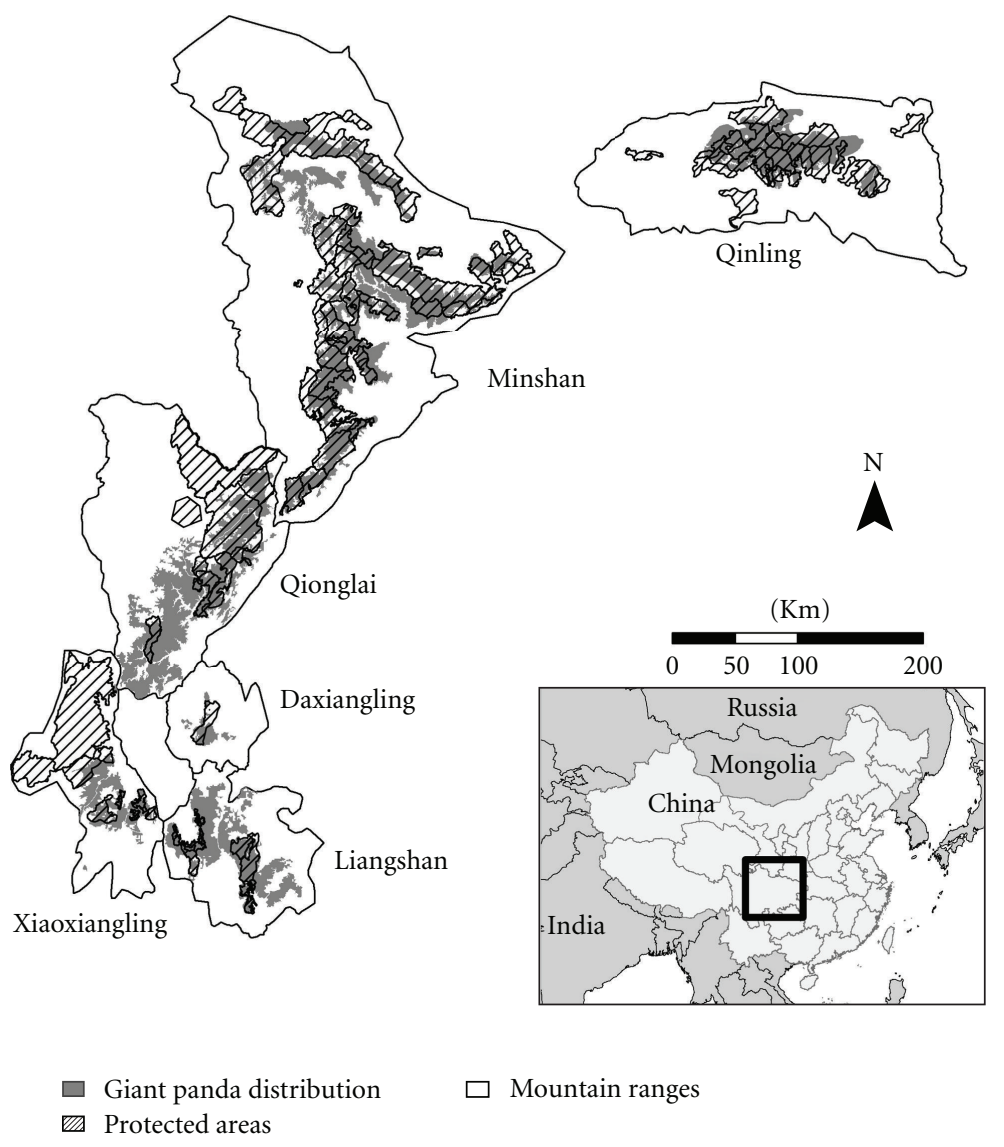

FIGURE 1: Current giant panda distribution, protected areas, and mountain ranges.

distribution and available general climate models (GCMs), we present a range-wide estimate for how climate change may affect giant panda habitats by the year 2080 and assess projected changes in fragmentation and protection levels. These data provide the most recent and informed estimate on how climate change will affect one of the most endangered and charismatic megavertebrates in the world. It also provides useful information as conservation organizations assess how to invest in giant panda conservation in the future.

\section{Methods}

2.1. Study Area. Our study encompassed six mountain ranges that constitute the extant geographic distribution of giant pandas: the Qinling, Minshan, Qionglai, Xiaoxangling, Daxiangling, and Liangshan $\left(102^{\circ} 00^{\prime}-108^{\circ} 11^{\prime} \mathrm{E}\right.$ and $27^{\circ} 53^{\prime}-33^{\circ} 55^{\prime} \mathrm{N}$; Figure 1$)$. Habitat types transition vertically through elevational changes within the giant panda distribution, from subtopical evergreen broad-leafed forest at lower elevations, to evergreen and deciduous broad-leafed forests, to mixed coniferous and deciduous broad-leafed forests, up to subalpine coniferous forests. There is a lot of variation in temperature and precipitation within the giant panda distribution and this, along with variation in soils, hydrology, slope, and aspect, have resulted in diverse plant and tree species [28]. Baseline data on giant panda distribution is from the most recent national survey for giant pandas. This data is not available to researchers outside China, making direct modeling of giant panda locations impossible [29]. However, habitat associations and models derived from the data have been made available. Our study assesses the effects of climate change on giant pandas indirectly, by measuring how climate change will alter the geographic distribution and extent of giant panda habitat.

The current distribution is primarily above $1,200 \mathrm{~m}$ elevation; however, giant pandas were found at elevations as low as $500 \mathrm{~m}$ during the last century [30]. As our study area we used the distribution of giant pandas from the national survey as a baseline and extended it to include contiguous areas down to $500 \mathrm{~m}$ elevation.

2.2. Climate Change Data. We obtained future climate projections from the WorldClim database [31] at 30' resolution for the year 2080. We included two general climate models; one described by the Canadian Centre for Climate Modeling and Analysis Coupled Model, version 3 (CGCM3) [32] and one from the Hadley Center for Climate Modeling Coupled Model, version 3 (HadCM3) [33]. Both are commonly used atmosphere-ocean coupled models and data is available for download (http://www.worldclim.org/). 
TABLE 1: Bioclim variables and their percent contribution and percent permutation importance reported by Maxent. Variables are in order of highest to lowest permutation importance.

\begin{tabular}{|c|c|c|c|}
\hline Variable & Description & $\begin{array}{c}\text { Permutation } \\
\text { importance }(\%)\end{array}$ & $\begin{array}{c}\text { Variable } \\
\text { contribution } \\
(\%)\end{array}$ \\
\hline Bio10 & Mean temperature of warmest quarter & 19.6 & 36.4 \\
\hline Bio15 & Precipitation seasonality (coefficient of variation) & 18.0 & 9.7 \\
\hline Bio7 & Temperature Annual Range (Bio5-Bio6) & 9.5 & 5.7 \\
\hline Biol2 & Annual Precipitation & 8.3 & 2.9 \\
\hline Bio4 & Temperature seasonality (standard deviation *100) & 8.0 & 6.1 \\
\hline Bio6 & Min temperature of coldest month & 7.6 & 17.1 \\
\hline Bio3 & Temperature change/no change (Bio2/Bio7) $(* 100)$ & 6.5 & 4.6 \\
\hline Biol1 & Mean temperature of coldest quarter & 5.0 & 1.6 \\
\hline Bio2 & Mean diurnal range (mean of monthly (maximum-minimum temperature) & 4.6 & 5.1 \\
\hline Bio17 & Precipitation of driest quarter & 2.8 & 6.2 \\
\hline Bio14 & Precipitation of driest month & 2.8 & 0.2 \\
\hline Biol8 & Precipitation of warmest quarter & 1.7 & 0.7 \\
\hline Bio9 & Mean temperature of driest quarter & 1.5 & 0.2 \\
\hline Biol & Annual mean temperature & 1.4 & 0.1 \\
\hline Slope & Angle of slope & 1.2 & 0.5 \\
\hline Aspect & Direction of slope & 0.8 & 0.8 \\
\hline Bio8 & Mean temperature of wettest quarter & 0.5 & 0.1 \\
\hline Bio5 & Max temperature of warmest month & 0.1 & 1.9 \\
\hline Bio13 & Precipitation of wettest month & 0.1 & 0.2 \\
\hline Bio19 & Precipitation of coldest quarter & 0.0 & 0.0 \\
\hline Bio16 & Precipitation of wettest quarter & 0.0 & 0.0 \\
\hline
\end{tabular}

We restricted our study to models constrained by the conditions outlined in the A2 scenario of the Special Report on Emissions Scenarios [34]. A1 and A2 families assume more rapid economic development than B1 and B2 families, which also assume more ecologically responsible societies by the year 2100 [35]. The A2 family assumes more heterogeneous future societies with regionally divergent economic growth and more fragmented growth in technological changes while the Al scenario assumes the world will be more homogeneous with similar standard of living levels and technological progress among various regions. Population is assumed to continually increase in the A2 scenario, but the A1 scenario assumes population will decline after reaching 9 billion. We chose the A2 scenario based on current trends in China where fossil-fuel $\mathrm{CO}_{2}$ emissions have doubled since 2000 [36], population has doubled since 1960 [37], GDP has grown nearly 40-times since 1960 [38], and other environmental indicators have shown steady declines in recent years [39]. IPCC author Richard Tol has asserted that the A2 family is by far the most realistic [40]. The A2 is a strong scenario and should help us identify patterns and trends in predicted changes to giant panda habitat.

For each climate dataset, bioclimatic parameters from monthly precipitation and minimum and maximum temperatures were interpolated using BIOCLIM [41]. We selected 19 of the 35 BIOCLIM variables which seemed most relevant (Table 1). These bioclimatic parameters are calculated across the entire year to offer a wider range of climatic variables for analysis.

We used Maxent to relate current giant panda distribution to environmental variables and to project future giant panda habitat. Maxent (http://www.cs.princeton.edu/ schapire/maxent/) is a general-purpose species distribution model that can make predictions from incomplete information with a high prediction success, particularly in cases with presence-only data $[41,42]$. Maxent estimates the species' distributions by finding the probability distribution of maximum entropy (i.e., the mean of each variable in the projected distribution is close to means of the observed data) subject to the constraints of where data is actually available [43]. For our study we created 1,500 random points inside the study area, which represents approximately 1 point for every $100 \mathrm{~m}^{2}$. We created 10,000 randomly sampled points in the study area and extracted the 19 BIOCLIM variables for both of the GCMs for the year 2080 to serve as background points for projecting future distributions. Digital elevation models (DEMs) at $90 \mathrm{~m}$ resolution from CGIAR-CSI SRTM [44] were used for elevation and to calculate slope and aspect; all three variables were added as model variables. Current climatic conditions of each point were interpolated and projected into the two future climate models. For both models we used 1 for the regularization multiplier, a convergence threshold of $10^{-5}$ and a maximum of 500 iterations based on the default recommendations.

Model performance was measured using the area under the receiver operating characteristic curve (AUC). AUC ranges from 0.5 , which is no better than random, up to 1.0 which represents perfect discriminatory capacity; AUC values over 0.75 are considered useful [45]. Maxent estimates the importance of the variables with percent contribution and permutation importance values. Percent contribution represents how much the variable contributed to the model 
based on the path selected for a particular run. Permutation importance is determined by changing the predictors' values between presence and background points and observing how that affects the AUC. The permutation importance depends on the final model, not the path used in an individual run and therefore is better for evaluating the importance of a particular variable. Standard errors and confidence intervals for both of the models were calculated in R v2.13.0 [46] using ROCR [47], vcd [48], and boot [49] packages. We assessed how well Maxent could predict the known current giant panda using the same methods, except we used GCMs for the year 2000 instead of 2080. Maxent was 77\% accurate in modeling current giant panda distribution.

We imported the Maxent probability distributions for each model into ArcGIS 9.3 (ESRI Inc., Redlands, CA) and converted them to presence/absence $(0 / 1)$ based on the threshold value that maximizes training sensitivity and plus specificity [50].

\subsection{Quantifying Suitable Habitat and Fragmentation. Areas} with dense human populations and roads are not suitable for giant pandas and croplands do not provide suitable habitat, therefore we removed croplands, urban areas, and human disturbance buffers. Based on a framework developed by Liu et al. [51], we considered areas within $1410 \mathrm{~m}$ of cities and $210 \mathrm{~m}$ of roads (city and transportation network data from NIMA [52]) to be unsuitable. We used land cover data from Global Land Cover 2000 [53]. Human development excludes giant pandas from areas $<1,200 \mathrm{~m}$ in elevation [30], so these areas were also removed from projected suitable habitat. After removing human disturbance and unsuitable land cover we calculated the size of all remaining patches. We then removed all patches $<4 \mathrm{~km}^{2}$ based on the average panda home range size [54]. For each of the three models (current giant panda distribution and two predictions) we calculated presence area within each mountain range and the amount and percent area inside protected areas.

We calculated the number of patches $>4 \mathrm{~km}^{2}$ and the number of these patches $>200 \mathrm{~km}^{2}$ remaining. An area this size would support typical giant panda home ranges $\left(\sim 4 \mathrm{~km}^{2}\right)$ for about 50 individuals, representing a population minimum needed to deter inbreeding depression [55, 56]. We used FRAGSTATS [57] to measure fragmentation indices within mountain ranges for each model, specifically the number of patches, mean patch size (MPS), and mean nearest neighbor distance (MNN). Nearest neighbor for each patch is the single shortest distance to another patch.

\section{Results}

3.1. Current Giant Panda Distribution. The current giant panda distribution includes at least 18 large patches $\left(>200 \mathrm{~km}^{2}\right)$ still intact (Table 2; Figure 1). The Minshan Mountains, supporting more than $40 \%$ of the giant panda population, have the largest suitable habitat area and the Daxiangling Mountains have the smallest. Larger mountain ranges with more of the remaining giant panda distribution have higher proportions protected than the smaller mountain ranges. The Qinling, Minshan, and Qionglai Mountain ranges combined account for nearly $90 \%\left(13,500 \mathrm{~km}^{2}\right)$ of the protected area within the giant panda distribution (Table 2). Percentages range from $25 \%$ in the Liangshan Mountains up to $72 \%$ protected in the Qinling Mountain range.

Fragmentation indices vary considerably across mountain ranges with an MPS ranging from $73 \mathrm{~km}^{2}$ (Daxiangling) to $863 \mathrm{~km}^{2}$ (Minshan) and MNN distances from 0.3 to $5.5 \mathrm{~km}$ (mean $1.5 \mathrm{~km}$; Table 3). The Qinling and Minshan Mountains have lower levels of fragmentation, having the largest MPS (509 $\mathrm{km}^{2}$ and $863 \mathrm{~km}^{2}$, resp.) and below average MNN distances $(0.3 \mathrm{~km}$ and $1.2 \mathrm{~km})$. The three southern mountain ranges are highly fragmented with few large patches remaining.

3.2. Projected Impacts of Climate Change. Our models tested well with an AUC of 0.752, standard error of 0.010 , and a $95 \%$ confidence interval of $0.992,1.000$. The most important variable based on permutation importance was mean temperature of the warmest quarter $(19.6 \%)$, followed closely by seasonality of precipitation (18\%, Table 1$)$. The next variable on the list, dropping 10 percentage points, is annual temperature range $(9.5 \%)$, followed by annual precipitation $(8.3 \%)$ and temperature seasonality (8.0\%). All other precipitation variables, such as precipitation of the driest quarter, driest month, warmest quarter, wettest month, coldest quarter, and wettest quarter had permutation importance of less than $3.0 \%$. Average temperatures for the year, the wettest quarter, and the driest quarter were also less than 3.0\%, along with slope and aspect.

Less than half of the current giant panda distribution is projected to be suitable by 2080 according to both climate models. Current distribution areas projected to be suitable in 2080 can be considered to be remaining habitat, as opposed to current distribution areas projected to be not suitable which can be considered lost habitat. Areas projected to be suitable in 2080 falling outside the current distribution represent potential new habitat areas. The amount and percentage of suitable habitat projected to be lost is nearly $60 \%$ for both climate scenarios (Table 2, Figure 2). Projected habitat lost varies between models and among mountain ranges. The far northern range in the Qinling Mountains is projected to fare best; the CGCM3 projects less than 1\% loss while the HadCM3 projects a $17 \%$ loss in suitable habitat. For all other mountain ranges the models project higher losses of between 60 to $97 \%$. Both models project the three southern ranges would retain little suitable habitat. Predicted losses are accompanied by declines in amount of suitable habitat that is protected. The Qinling Mountains fare the best with approximately $70 \%$ of the suitable habitat protected in 2080 . Other mountain ranges show only $1-28 \%$ of suitable habitat area protected.

Despite the predicted losses within the current giant panda distribution, there is an overall increase in suitable habitat projected outside the current distribution (Tables 2 and 4, Figure 2). Both models project considerable amounts of potential new habitat outside the current distribution of giant pandas - an additional $34,200 \mathrm{~km}^{2}$ (CGCM3) and $24,300 \mathrm{~km}^{2}$ area (HadCM3) (Table 4). However, most potential new areas are not contiguous with the current 


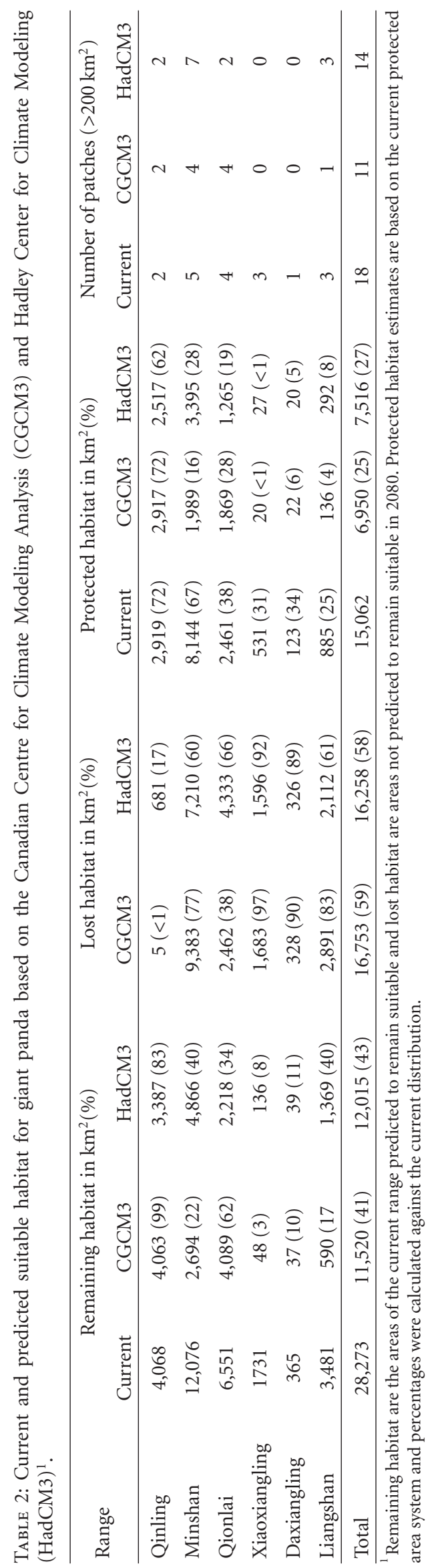



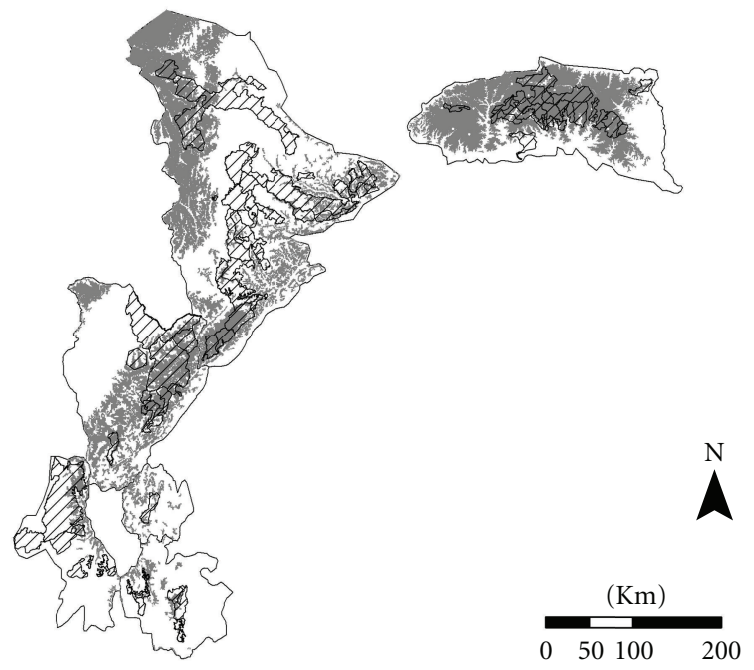

$\square$ CGCM3 projected habitat Protected areas
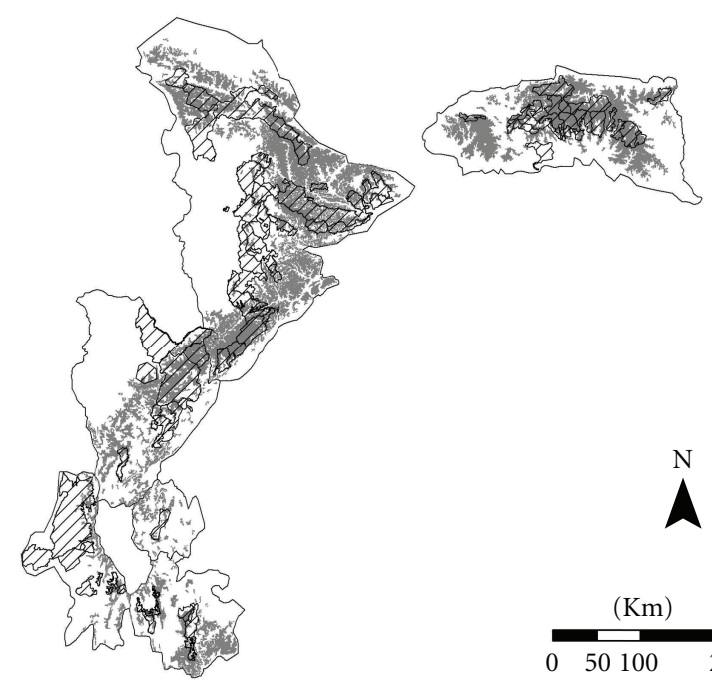

$\square$ HadCM3 projected habitat Q Protected areas

(a)

(b)

Figure 2: Predicted suitable habitat for the year 2080 based on (a) Canadian Centre for Climate Modeling and Analysis Coupled Model, version 3 (CGCM3), (b) Hadley Center for Climate Modeling Coupled Model, version 3 (HadCM3), and protected status based on the existing protected area system.

TABle 3: Fragmentation metrics for the current and future suitable habitat for giant panda based on the Canadian Centre for Climate Modeling Analysis (CGCM3) and Hadley Center for Climate Modeling (HadCM3).

\begin{tabular}{|c|c|c|c|c|c|c|c|c|c|}
\hline \multirow{2}{*}{ Range } & \multicolumn{3}{|c|}{ Mean patch size $\left(\mathrm{km}^{2}\right)$} & \multicolumn{3}{|c|}{ Mean nearest neighbor $\left(\mathrm{km}^{2}\right)$} & \multicolumn{3}{|c|}{ Number of patches } \\
\hline & Current & CGCM3 & HadCM3 & Current & CGCM3 & HadCM3 & Current & CGCM3 & HadCM3 \\
\hline Qinling & 509 & 508 & 338 & 0.3 & 0.3 & 0.6 & 8 & 8 & 10 \\
\hline Minshan & 863 & 46 & 75 & 1.2 & 1.2 & 1.5 & 14 & 55 & 63 \\
\hline Qionglai & 468 & 5 & 32 & 0.8 & 0.7 & 1.7 & 14 & 88 & 68 \\
\hline Xiaoxiangling & 286 & 7 & 11 & 5.5 & 3.2 & 6.5 & 6 & 7 & 12 \\
\hline Daxiangling & 73 & 11 & 10 & 2.5 & 3.8 & 1.0 & 5 & 3 & 4 \\
\hline Liangshan & 387 & 65 & 47 & 0.6 & 4.2 & 1.6 & 9 & 9 & 29 \\
\hline Total & 505 & 67 & 38 & 1.5 & 1.2 & 1.8 & 56 & 170 & 186 \\
\hline
\end{tabular}

giant panda distribution and some patches are as far as $120 \mathrm{~km}$ away (average of $22 \mathrm{~km}$ for CGCM3 and $13 \mathrm{~km}$ for HadCM3). Potential new habitat includes some areas at elevations $(>3,500 \mathrm{~m})$ that are not often used by giant pandas today-approximately $10,100 \mathrm{~km}^{2}$ (CGCM3) and 4,900 km² (HadCM3) are above 3,500 $\mathrm{m}$ (Table 4). Another concern is that much of this potential new habitat would not fall within the existing protected area system; only $12 \%$ of the CGCM3 and $14 \%$ of the HadCM3 potential new habitat area would be protected under the current protected area system (Table 4, Figure 2).

Substantial portions of both climate projection models were removed due to human disturbance (cropland, urban area, settlements, and roads), illustrating the highly fragmented nature of the remaining giant panda range. Approximately $21,840 \mathrm{~km}^{2}$ and $11,690 \mathrm{~km}^{2}$ were removed from the initial CGCM3 and HadCM2 models, respectively.
Comparing fragmentation metrics between current giant panda distribution and projected suitable habitat area for 2080 indicates major increases in fragmentation within all mountain ranges. The projected number of patches more than triples in both models (Tables 1 and 2). The MPS overall drops dramatically from $505 \mathrm{~km}^{2}$ in the current distribution down to $67 \mathrm{~km}^{2}$ (CGCM3) and $38 \mathrm{~km}^{2}$ (HadCM3) in 2080 (Table 3 ). Within the mountain ranges both models project increased isolation between patches, with MNN increasing in all mountain ranges, with three exceptions; the CGCM3 projects a decrease in MNN within the Qionglai and Xiaoxiangling ranges and the HadCM3 projects a decrease in MNN in the Daxiangling range. Both models also show a reduction in large patches $\left(>200 \mathrm{~km}^{2}\right)$, from 18 to 14 or less (Table 2). However, both the Qinling and Minshan Mountains retain large patches, and fewer fragmentation effects are predicted. 


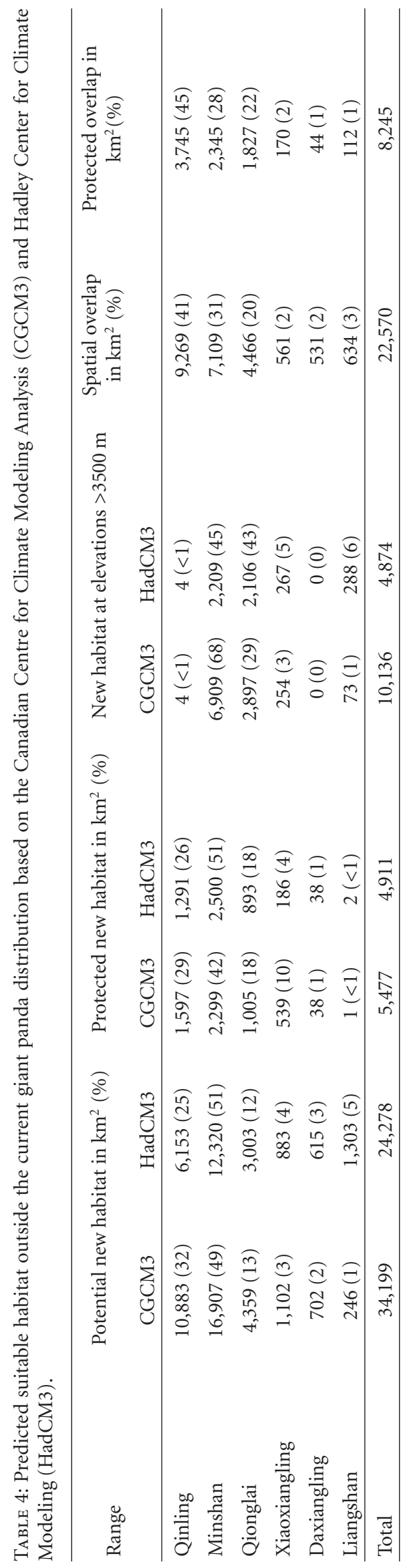




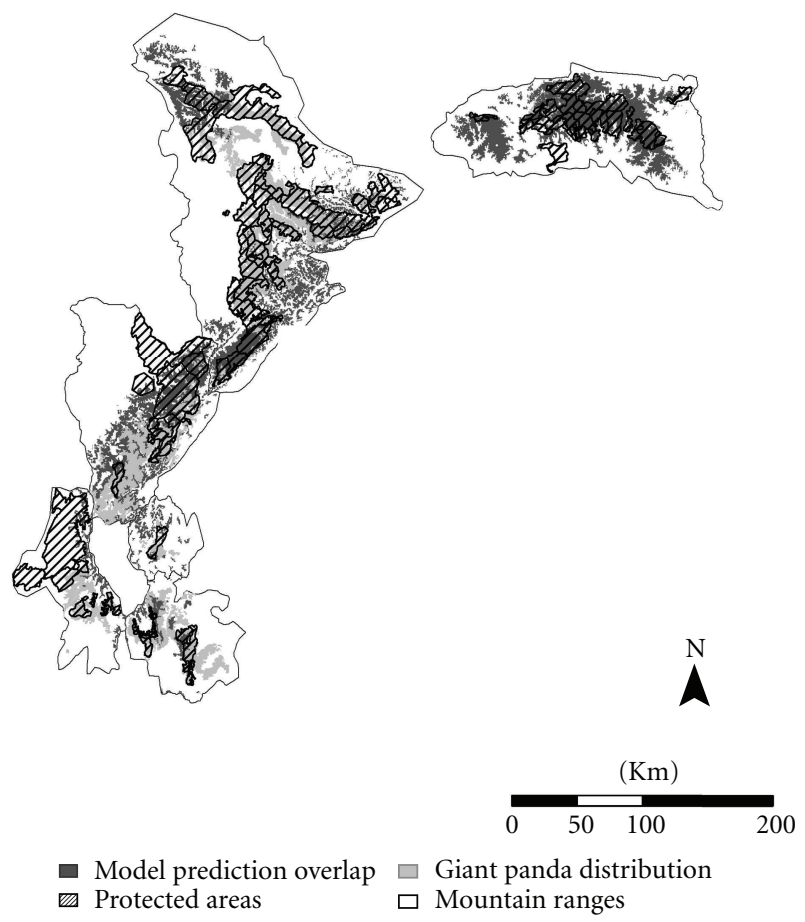

FIGURE 3: Spatial agreement for predictions of suitable habitat in 2080 based on the Canadian Centre for Climate Modeling and Analysis Coupled Model version 3 and the Hadley Center for Climate Modeling Coupled Model version 3, the current giant panda distribution, and protected status based on the existing protected area system.

The projected suitable habitat for the two models has only $38 \%$ spatial agreement (Table 4 , Figure 3 ). The most similar projections are found in the Qinling Mountains $(61 \%)$ while the lowest are found in the Liangshan Mountains $(22 \%)$.

\section{Discussion}

4.1. Climate Change Effects on Geographic Distribution and Extent of Giant Panda Habitat. Our results project major losses within the giant panda's present distribution by 2080, supporting a major general prediction of climate changethe shift of vegetation regimes towards higher altitudes and latitudes. About $90 \%$ of the future suitable habitat occurs in the three northern mountain ranges while the southern mountain ranges show a $>80 \%$ decrease in suitable habitat. The far northern Qinling Mountains fare best, retaining the largest proportion of suitable habitat, showing a significant increase in new suitable habitat, maintaining large MPSs and small MNNs. Generally giant pandas are projected to follow climate effect patterns (i.e., altitudinal and latitudinal shifts) previously observed for many bird and butterfly species [5860], mammals [61, 62], and a range of other taxa [18]. Many of the previous studies give direct evidence that northward shifts are already happening.

Our results project upward elevational shifts, with more than a quarter of the new presence areas predicted to be above 3,500 m. Evidence of an overall upward shift in optimum elevation due to climate change exists for many plant species in temperate forests of western Europe between 1905 and 2005 [63]. Similar patterns have emerged for some butterflies in the Czech Republic [64] and Spain [65], vegetation in the Alps [66], and some birds in Southeast Asia [67].

Giant pandas may be particularly at risk from shifting vegetation regimes. Not only do they specialize on bamboo, but they may eat only two or three bamboo species, depending on their region, despite the presence of other bamboo species (e.g., [2, 68, 69]). We currently cannot predict impacts of climate change on various bamboo species or whether they will remain at lower elevations, shift upslope, or do both. Here we make the assumption that all future suitable habitat will be usable; however, it is possible that some of the higher elevation areas are unsuitable for vegetation due to rocky cover.

Our results may be a conservative estimate of climate change effects on giant pandas. First our models are based on the assumption that agriculture will not advance above $\sim 1,200 \mathrm{~m}$. This assumption may not hold if warming results in higher elevations becoming suitable for crops. If agricultural use shifts up to higher elevations it will exclude giant pandas from those areas.

Finally, we may be underestimating future forest cover. During the past decade the Chinese government has enacted two major initiatives to protect forest and restore giant panda habitat. These include the Grain-to-Green Program, which compensates farmers for returning steep cropland to forest, and the Natural Forest Conservation Program, which bans harvest of natural forests and provides economic incentives to locals for enforcement against tree harvest $[7,70]$. Research in Wolong Nature Reserve suggests that these 
programs have helped restore habitat [71]. Expansion of suitable areas into higher elevations could also increase connectivity in some places.

4.2. Adaptation Strategies. The momentum of climate change already underway will likely result in changes to natural systems, regardless of any current or future efforts to mitigate emissions $[72,73]$. Results of our work could help inform adaptation strategies to help ameliorate predicted impacts of climate change on giant pandas and their habitat by identifying areas that are likely to have drastic changes, those that are expected to fare better and are already well protected, and those that are expected to fare well but are not currently protected.

China's government has already made key steps that would top the list for any adaptation strategies developed for giant pandas. In addition to the restoration programs currently underway they have greatly expanded the amount of protected area in recent decades. The number of giant panda protected areas has increased from only 12 in 1980 to 33 by the year $2000[2,68]$, and currently there are more than 59 protected areas [74]. Still, just 60\% of giant pandas are currently found within protected areas [29]. Our results show that there is great potential for expanding protected status to areas identified as suitable, as well as for increasing connectivity within ranges to help facilitate movements between small populations.

Both our models predict the Qinling Mountains will maintain most of its habitat and that fragmentation will be minimal even under various climate change scenarios. Suitable habitat is estimated to double or triple in the Qinling Mountains by 2080 , though only $15 \%$ would be protected and extending protection to new areas could help enhance the Qinling population. In contrast, the Minshan and the Qionglai are expected to lose more than half their current suitable habitat. Both mountain ranges are predicted to have a considerable amount of new areas becoming suitable, but with low levels of protection. Both our models project suitable habitat buffering existing protected areas in the far south and the northwest corner of the Minshan Mountains. In the Qionglai Mountains both our models project a substantial amount of suitable habitat between the large group of protected areas and the lone protected area to in the south to remain suitable in 2080. These areas could be especially important because they already support giant panda populations but are not yet protected, and they could enhance connectivity within the Qionglai range. The Minshan and the Qionglai mountain ranges have the largest and second largest giant panda populations and should be prioritized for increased protection to help stabilize them against the impacts of climate change.

Our results predict a particularly dire situation in the small southern mountain ranges. These three mountain ranges are predicted to be the most fragmented as a result of climate change-no large patches are predicted for the Xiaoxingling and Daxiangling and only a few for the Liangshan. Though habitat is expected to decline in the three larger ranges, a similar number of large patches is predicted to remain. According to the 2000-2001 Third National Survey, the 3 smaller ranges currently support 115 (Liangshan), 32 (Xiaoxiangling), and 29 (Daxiangling) giant pandas. The drastic decline predicted for the southern ranges raises difficult questions which should be considered when developing adaptation strategies. Small populations currently reported from the south are likely the result of the isolation and fragmentation of subpopulations, which may already be causing reduced genetic diversity. While it is important to maintain these small populations for maintenance of the overall genetic diversity of the metapopulation, it may be more effective to prioritize protection of areas that are most likely to remain suitable even with expected changes in climate. Translocation is a tool that may be useful in adaptation strategies if habitat losses in the south become severe enough to warrant moving small populations to areas where they have a better chance for survival. This could help bolster other populations against risk of extinction.

Though our climate models only have a $40 \%$ agreement, there is still a large amount of area $\left(22,570 \mathrm{~km}^{2}\right)$ that both models predict as suitable in 2080 and less than a quarter of this area is currently protected. These areas, particularly those close to current giant panda populations, should be explored via field surveys to assess suitability and should potentially become high priorities for protection. Once key areas are identified they should also be considered for future protection and for new conservation initiatives, such as planning for reintroduction of captive pandas into the wild.

Corridors and increased connectivity also must be prioritized in any adaptation strategy designed to mitigate impacts of climate change on giant pandas. Our model estimates of forest fragmentation, one of the greatest threats to giant pandas, increase dramatically by the year 2080, with reduced patch size, increased isolation, and fewer large patches that can support populations in the long term. Much of the habitat in 2080 is not connected to the current giant panda distribution. Based on radiotelemetry data giant pandas typically move $<500 \mathrm{~m} /$ day [54] and thus are unlikely to be able to adjust to increased fragmentation at the necessary scale predicted by our models. This is especially critical to giant panda survival since previous research demonstrated that increased connectivity is needed to improve gene flow and maintain genetic diversity. A majority of the remaining populations have 20 pandas or fewer $[3,5,75]$, putting them at risk of inbreeding and extirpation $[4,76]$. Enhancing their chance for survival will depend on improving connectivity by increasing protection of suitable habitat and establishing corridors to connect isolated populations $[4,68,76]$.

4.2.1. Measuring Influence of Climate Variables. Based on Maxent's permutation importance values, temperature during the warmest quarter was the most important variable and annual amount of precipitation was high-both have also been shown to influence growth rates of bamboo [77]. Permutation importance values also illustrate the influence of seasonality on the model, with both precipitation and temperature seasonality along with annual temperature range reported in the top five most important variables. Extensive analysis of satellite imagery and the $\mathrm{CO}_{2}$ records between 1981-1991 has shown that changes in seasonality 
are associated with changes in air temperatures and provide evidence that the warmer temperatures are promoting increased vegetative growth [78]. Seasonality is a key factor in the growth and distribution of bamboo and will be a key factor in future habitat suitability.

4.2.2. Model Limitations. Though climate envelope models are widely used in climate change research to predict future species distributions [26, 27], there are limitations. Ibáñez et al. [79] point out that this approach effectively treats the realized niche as though it were the fundamental niche. Changes in climate may also affect how a species can disperse, influence reproductive capacity, and disrupt ecosystem functioning as key species move in or out of an area at varying rates [80], while the landscape mosaic and human activities may impede or facilitate migration to different degrees for different species [81]. We expanded the current giant panda distribution layer to include lower elevations to better reflect the fundamental niche of giant pandas, and have incorporated human use as much as possible by removing incompatible human disturbance based on current data. Though we cannot include all potential influences in the model, our results represent the current state-of-theart in analyzing the impacts of climate change on species distributions and are based on the best data available for giant pandas. We believe that for landscape purposes it is likely a good representation of how climate change will affect the patterns and distribution of giant panda habitat.

4.3. Conclusions. Giant panda habitat and the effectiveness of protecting this habitat will be severely affected by climate change. Using well-established modeling procedures we provide essential guidance for developing adaptation strategies, designing future surveys, and prioritizing protection of giant panda habitat. Our results are consistent with previous studies on climate change effects on montane species. Our research provides compelling evidence to increase protected area development in the northern and central ranges of the current giant panda distribution and for ensuring increased connectivity between currently existing and potential future suitable areas.

\section{Acknowledgments}

The authors would like to thank Peter Leimgruber for reviewing and editing many versions of this paper, and for providing valuable comments and suggestions. This paper was funded by the Friends of the National Zoo.

\section{References}

[1] J. Schipper, J. S. Chanson, F. Chiozza et al., "The status of the world's land and marine mammals: diversity, threat, and knowledge," Science, vol. 322, no. 5899, pp. 225-230, 2008.

[2] G. B. Schaller, J. Hu, W. Wenshi, and J. Zhu, The Giant Pandas of Wolong, University of Chicago Press, Chicago, Ill, USA, 1985.

[3] Ministry of Forestry and World Wide Fund for Nature, National Conservation Management Plan for the Giant Panda and
Its Habitat: Sichuan, Shaanxi and Gansu Provinces, the People's Republic of China, Ministry of Forestry, Beijing and WWF International, Gland, Switzerland, 2006.

[4] S. J. O'Brien, W. Pan, and Z. Lu, "Pandas, people and policy," Nature, vol. 369, no. 6477, pp. 179-180, 1994.

[5] J. MacKinnon and R. De Wulf, "Designing protected areas for giant pandas in China," in Mapping the Diversity of Nature, R. I. Miller, Ed., Chapman and Hall, London, UK, 1994.

[6] J. Hu, Research on the Giant Panda, Shanghai Publishing House of Science and Technology, Shanghai, China, 2001.

[7] W. Xu, Z. Ouyang, A. Viña, H. Zheng, J. Liu, and Y. Xiao, "Designing a conservation plan for protecting the habitat for giant pandas in the Qionglai mountain range, China," Diversity and Distributions, vol. 12, no. 5, pp. 610-619, 2006.

[8] R. Lande, "Genetics and demography in biological conservation," Science, vol. 241, no. 4872, pp. 1455-1460, 1988.

[9] K. Ralls, K. Brugger, and J. Ballou, "Inbreeding and juvenile mortality in small populations of ungulates," Science, vol. 206, no. 4422, pp. 1101-1103, 1979.

[10] S. H. Schneider and T. L. Root, "Climate change," in Status and Trends of the Nation's Biological Resources, M. J. Mac, P. A. Ople, C. E. Puckett Haecke, and P. D. Doran, Eds., United States Geological Survey, Reston, Va, USA, 1998.

[11] IPCC, "Climate Change 2001: The Scientific Basis in Contribution of Working Group I to the 3rd Assessment Report of the Intergovernmental Panel on Climate Change," Cambridge University Press, Cambridge, UK, 2001.

[12] J. Reilly, P. H. Stone, C. E. Forest, M. D. Webster, H. D. Jacoby, and R. G. Prinn, "Climate change: uncertainty and climate change assessments," Science, vol. 293, no. 5529, pp. 430-433, 2001.

[13] T. M. L. Wigley and S. C. B. Raper, "Interpretation of high projections for global-mean warming," Science, vol. 293, no. 5529, pp. 451-454, 2001.

[14] K. A. McDonald and J. H. Brown, "Using montane mammals to model extinctions due to global change," Conservation Biology, vol. 6, no. 3, pp. 409-415, 1992.

[15] J. P. McCarty, "Ecological consequences of recent climate change," Conservation Biology, vol. 15, no. 2, pp. 320-331, 2001.

[16] A. D. Barnosky, E. A. Hadly, and C. J. Bell, "Mammalian response to global warming on varied temporal scales," Journal of Mammalogy, vol. 84, no. 2, pp. 354-368, 2003.

[17] E. P. Lessa, J. A. Cook, and J. L. Patton, "Genetic footprints of demographic expansion in North America, but not Amazonia, during the Late Quaternary," Proceedings of the National Academy of Sciences of the United States of America, vol. 100, no. 18, pp. 10331-10334, 2003.

[18] C. Parmesan and G. Yohe, "A globally coherent fingerprint of climate change impacts across natural systems," Nature, vol. 421, no. 6918, pp. 37-42, 2003.

[19] T. L. Root, J. T. Price, K. R. Hall, S. H. Schneider, C. Rosenzweig, and J. A. Pounds, "Fingerprints of global warming on wild animals and plants," Nature, vol. 421, no. 6918, pp. 5760, 2003.

[20] R. Guralnick, "The legacy of past climate and landscape change on species'current experienced climate and elevation ranges across latitude: a multispecies study utilizing mammals in western North America," Global Ecology and Biogeography, vol. 15, no. 5, pp. 505-518, 2006.

[21] J. J. Lawler, D. White, R. P. Neilson, and A. R. Blaustein, "Predicting climate-induced range shifts: model differences and model reliability," Global Change Biology, vol. 12, no. 8, pp. 1568-1584, 2006. 
[22] R. L. Peters and J. D. S. Darling, "The greenhouse effect and nature reserves. Global warming would diminish biological diversity by causing extinctions among reserve species," BioScience, vol. 35, no. 11, pp. 707-717, 1985.

[23] J. L. Isaac, J. Vanderwal, C. N. Johnson, and S. E. Williams, "Resistance and resilience: quantifying relative extinction risk in a diverse assemblage of Australian tropical rainforest vertebrates," Diversity and Distributions, vol. 15, no. 2, pp. 280-288, 2009.

[24] IUCN, Species Susceptibility to Climate Change Impacts, IUCN, World Conservation Union, Gland, Switzerland, 2008.

[25] D. G. Reid, A. H. Taylor, Hu Jinchu, and Qin Zisheng, "Environmental influences on bamboo Bashania fangiana growth and implications for giant panada conservation," Journal of Applied Ecology, vol. 28, no. 3, pp. 855-868, 1991.

[26] B. Huntley, R. E. Green, Y. C. Collingham et al., "The performance of models relating species geographical distributions to climate is independent of trophic level," Ecology Letters, vol. 7, no. 5, pp. 417-426, 2004.

[27] R. J. Hijmans and C. H. Graham, "The ability of climate envelope models to predict the effect of climate change on species distributions," Global Change Biology, vol. 12, no. 12, pp. 2272-2281, 2006.

[28] C. Wang, The Forests of China, Harvard University Press, Cambridge, Mass, USA, 1961.

[29] State Forestry Administration of China, The Third National Survey Report on Giant Panda in China, Science Press, Beijing, China, 2006.

[30] W. Pan, Z. Gao, and Z. Lü, The Giant Panda's Natural Refuge in the Qinling Mountains, Peking University Press, Beijing, China, 1988.

[31] R. J. Hijmans, S. E. Cameron, J. L. Parra, P. G. Jones, and A. Jarvis, "Very high resolution interpolated climate surfaces for global land areas," International Journal of Climatology, vol. 25, no. 15, pp. 1965-1978, 2005.

[32] G. M. Flato, G. J. Boer, W. G. Lee et al., "The Canadian centre for climate modelling and analysis global coupled model and its climate," Climate Dynamics, vol. 16, no. 6, pp. 451-467, 2000.

[33] C. Gordon, C. Cooper, C. A. Senior et al., "The simulation of SST, sea ice extents and ocean heat transports in a version of the Hadley Centre coupled model without flux adjustments," Climate Dynamics, vol. 16, no. 2-3, pp. 147-168, 2000.

[34] Intergovernmental Panel on Climate Change (IPCC), Special Report on Emissions Scenarios, Edited by N. Narkicenovic and R. Swart, Cambridge University Press, Cambridge, UK, 2000.

[35] IPCC, "Summary for policymakers," in Climate Change 2007: The Physical Science Basis. Contribution of Working Group I to the Fourth Assessment Report of the Intergovernmental Panel on Climate Change, S. Solomon, D. Qin, M. Manning et al., Eds., Cambridge University Press, Cambridge, UK, 2007.

[36] T. A. Boden, G. Marland, and R. J. Andres, Global, Regional, and National Fossil-Fuel CO2 Emissions, Carbon Dioxide Information Analysis Center, Oak Ridge National Laboratory, U.S. Department of Energy, Oak Ridge, Tenn, USA, 2011.

[37] United Nations, Department of Economic and Social Affairs, Population Division, World Fertility Report 2009, New York, NY, USA, 2011.

[38] The World Bank, Global Purchasing Power parities and Real Expenditures: 2005 International Comparison Program, World Bank, Washington, DC, USA, 2008.

[39] Yale Center for Environmental Policy (YCELP) and Center for International Earth Science Information Network, 2010 Environmental Performance Index, Socioeconomic Data and Applications Center (SEDAC), Columbia University, New York, NY, USA, http://sedac.ciesin.columbia.edu/es/epi/ downloads.html.

[40] R. Tol, "Memorandum by Defra/HM treasury," in The Economics of Climate Change, Second Report of the 2005-2006 session, UK Parliament House of Lords Economics Affairs Select Committee, 2006.

[41] H. Nix, "A biogeographic analysis of Australian elaphid snakes," in Atlas of Elapid Snakes of Australia, Australian Government Publishing Service, 1986.

[42] J. Elith, C. H. Graham, R. P. Anderson et al., "Novel methods improve prediction of species' distributions from occurrence data," Ecography, vol. 29, no. 2, pp. 129-151, 2006.

[43] S. J. Phillips, R. P. Anderson, and R. E. Schapire, "Maximum entropy modeling of species geographic distributions," Ecological Modelling, vol. 190, no. 3-4, pp. 231-259, 2006.

[44] A. Jarvis, H. Reuter, E. Nelson, and E. Guevara, Hole-Filled Seamless SRTM Data V3, International Centre for Tropical Agriculture (CIAT), 2006.

[45] J. Elith, "Quantitative methods for modeling species habitat: comparative performance and an application to Australian plants," in Quantitative Methods for Conservation Biology, S. Ferson and M. Burgman, Eds., pp. 39-58, Springer, 2002.

[46] R Development Core Team, R: A Language and Environment for Statistical Computing, $R$ Foundation for Statistical Computing, Vienna, Austria, 2010.

[47] T. Sing, O. Sander, N. Beerenwinkel, and T. Lengauer, ROCR: Visualizing the performance of scoring classifiers, R package version 1.0-4, 2009, http://CRAN.R-project.org/package=ROCR.

[48] D. Meyer, A. Zeileis, and K. Hornik, vcd: Visualizing Categorical Data, R package version 1.2-9, 2010.

[49] A. Canty and B. Ripley, Boot: Bootstrap R (S-Plus) Functions, R package version 1.2-42, 2010.

[50] C. Liu, P. M. Berry, T. P. Dawson, and R. G. Pearson, "Selecting thresholds of occurrence in the prediction of species distributions," Ecography, vol. 28, no. 3, pp. 385-393, 2005.

[51] J. Liu, Z. Ouyang, W. W. Taylor, R. Groop, Y. Tan, and H. Zhang, "A framework for evaluating the effects of human factors on wildlife habitat: the case of giant pandas," Conservation Biology, vol. 13, no. 6, pp. 1360-1370, 1999.

[52] National Imagery and Mapping Agency (NIMA), Military Specification MIL-V-89033 Vector Smart Map (VMap) Level 1, 1995.

[53] European Commission Joint Research Centre, Global Land Cover 2000 database, 2003.

[54] X. Liu, A. K. Skidmore, T. Wang, Y. Yong, and H. H. T. Prins, "Giant panda movements in Foping Nature Reserve, China," Journal of Wildlife Management, vol. 66, no. 4, pp. 1179-1188, 2002.

[55] I. R. Franklin, "Evolutionary change in small populations," in Conservation Biology: An Evolutionary-Ecological Perspective, M. E. Soule and B. A. Wilcox, Eds., Sinauer, Sunderland, Mass, USA, 1980.

[56] M. E. Soule, "Thresholds for survival: maintaining fitness and evolutionary potential," in Conservation Biology: An Evolutionary-Ecological Perspective, M. E. Soule and B. A. Wilcox, Eds., Sinauer, Sunderland, Mass, USA, 1980.

[57] K. McGarigal, S. A. Cushman, M. C. Neel, and E. Ene, FRAGSTATS: Spatial Pattern Analysis Program for Categorical Maps, Computer Software Program, University of Massachusetts, Amherst, Mass, USA, 2002.

[58] C. Parmesan, “Climate and species' range," Nature, vol. 382, no. 6594, pp. 765-766, 1996. 
[59] C. D. Thomas, A. Cameron, R. E. Green et al., "Extinction risk from climate change," Nature, vol. 427, no. 6970, pp. 145-148, 2004.

[60] G. Grabherr, M. Gottfried, and H. Paull, "Climate effects on mountain plants," Nature, vol. 369, no. 6480, p. 448, 1994.

[61] P. Hersteinsson and D. W. Macdonald, "Interspecific competition and the geographical distribution of red and Arctic foxes Vulpes vulpes and Alopex lagopus," Oikos, vol. 64, no. 3, pp. 505-515, 1992.

[62] S. Payette, "Recent porcupine expansion at tree line: a dendroecological analysis," Canadian Journal of Zoology, vol. 65, no. 3, pp. 551-557, 1987.

[63] J. Lenoir, J. C. Gégout, P. A. Marquet, P. De Ruffray, and H. Brisse, "A significant upward shift in plant species optimum elevation during the 20th century," Science, vol. 320, no. 5884, pp. 1768-1771, 2008.

[64] M. Konvicka, M. Maradova, J. Benes, Z. Fric, and P. Kepka, "Uphill shifts in distribution of butterflies in the Czech Republic: effects of changing climate detected on a regional scale," Global Ecology and Biogeography, vol. 12, no. 5, pp. 403 410, 2003.

[65] R. J. Wilson, D. Gutiérrez, J. Gutiérrez, D. Martínez, R. Agudo, and V. J. Monserrat, "Changes to the elevational limits and extent of species ranges associated with climate change," Ecology Letters, vol. 8, no. 11, pp. 1138-1146, 2005.

[66] H. M. Pauli, M. Gottfried, and G. Grabherr, "Effects of climate change on the alpine and nival vegetation of the Alps," Journal of Mountain Ecology, vol. 7, pp. 9-12, 2003.

[67] K. S. H. Peh, "Potential effects of climate change on elevational distributions of tropical birds in Southeast Asia," Condor, vol. 109, no. 2, pp. 437-441, 2007.

[68] C. J. Loucks, Z. Lu, E. Dinerstein et al., "Giant pandas in a changing landscape," Science, vol. 294, no. 5546, p. 1465, 2001.

[69] W. Zhang, Y. Hu, B. Chen et al., "Evaluation of habitat fragmentation of giant panda (Ailuropoda melanoleuca) on the north slopes of Daxiangling Mountains, Sichuan province, China," Animal Biology, vol. 57, no. 4, pp. 485-500, 2007.

[70] P. Zhang, G. Shao, G. Zhao et al., "China's forest policy for the 21st century," Science, vol. 288, no. 5474, pp. 2135-2136, 2000.

[71] A. Viña, S. Bearer, X. Chen et al., "Temporal changes in giant panda habitat connectivity across boundaries of Wolong Nature Reserve, China," Ecological Applications, vol. 17, no. 4, pp. 1019-1030, 2007.

[72] J. R. Mawdsley, R. O’Malley, and D. S. Ojima, "A review of climate-change adaptation strategies for wildlife management and biodiversity conservation," Conservation Biology, vol. 23, no. 5, pp. 1080-1089, 2009.

[73] N. E. Heller and E. S. Zavaleta, "Biodiversity management in the face of climate change: a review of 22 years of recommendations," Biological Conservation, vol. 142, no. 1, pp. 14-32, 2009.

[74] J. Ran, B. Du, and B. Yue, "Conservation of the endangered giant panda ailuropoda melanoleuca in China: successes and challenges," Oryx, vol. 43, no. 2, pp. 176-178, 2009.

[75] G. B. Schaller, The Last Panda, University Of Chicago Press, Chicago, Ill, USA, 1993.

[76] S. J. O'brien and J. A. Knight, "The future of the giant panda," Nature, vol. 325, no. 6107, pp. 758-759, 1987.

[77] N. Rao, X. P. Zhang, and S. L. Zhu, Selected Papers on Recent Bamboo Research in China, Bamboo Information Centre, Chinese Academy of Forestry, 1991.
[78] R. B. Myneni, C. D. Keeling, C. J. Tucker, G. Asrar, and R. R. Nemani, "Increased plant growth in the northern high latitudes from 1981 to 1991," Nature, vol. 386, no. 6626, pp. 698$702,1997$.

[79] I. Ibáñez, J. S. Clark, M. C. Dietze et al., "Predicting biodiversity change: outside the climate envelope, beyond the speciesarea curve," Ecology, vol. 87, no. 8, pp. 1896-1906, 2006.

[80] M. Loreau, S. Naeem, P. Inchausti et al., "Ecology: biodiversity and ecosystem functioning: current knowledge and future challenges," Science, vol. 294, no. 5543, pp. 804-808, 2001.

[81] Y. C. Collingham and B. Huntley, "Impacts of habitat fragmentation and patch size upon migration rates," Ecological Applications, vol. 10, no. 1, pp. 131-144, 2000. 

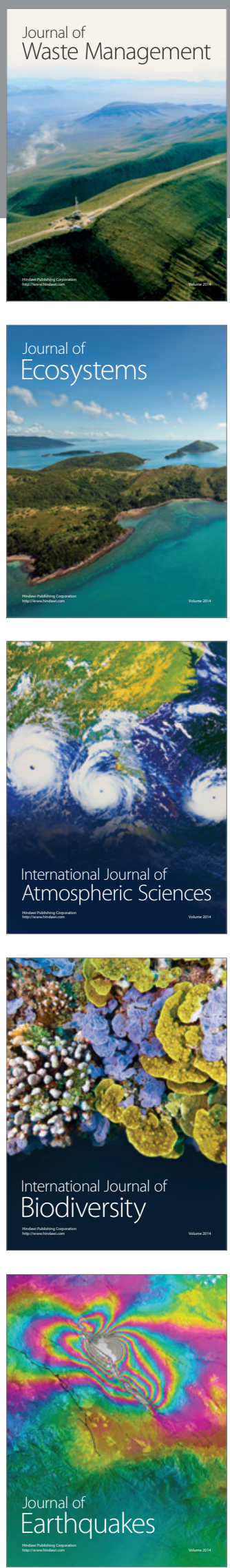
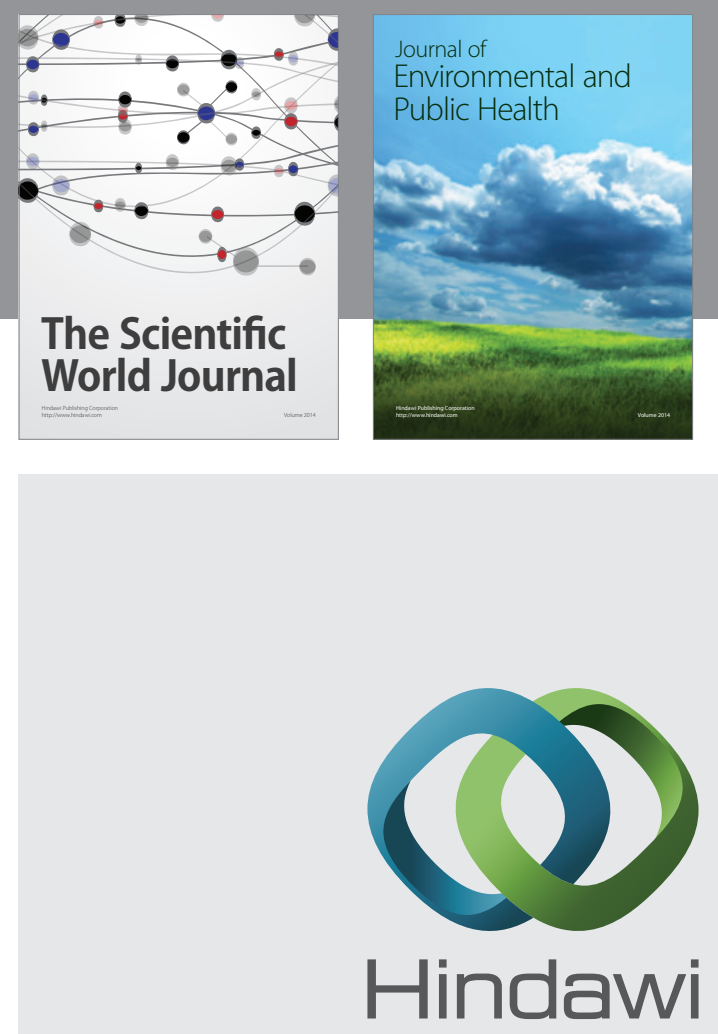

Submit your manuscripts at

http://www.hindawi.com
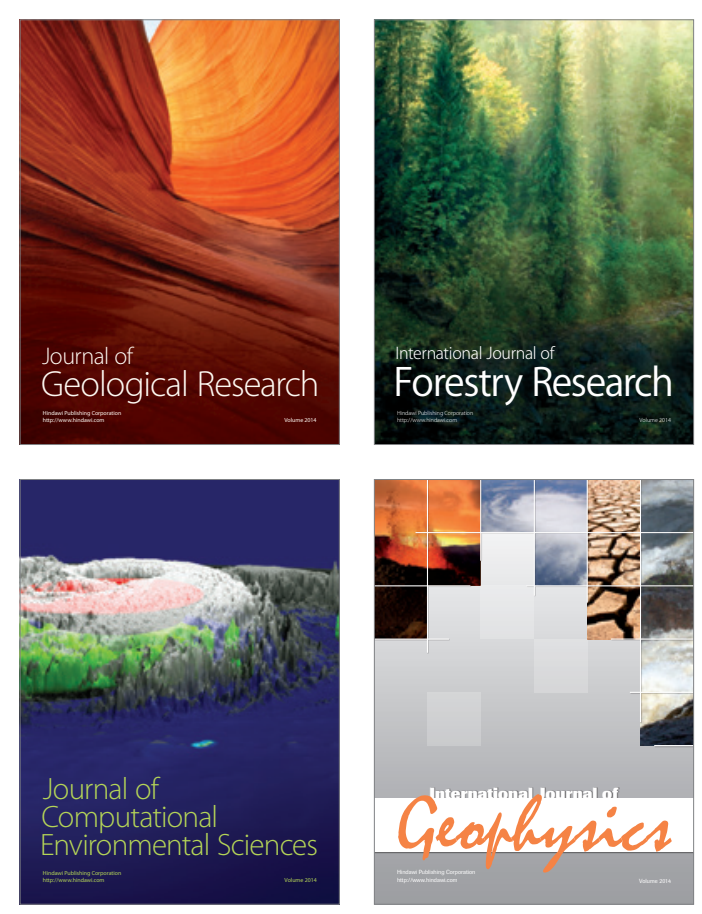
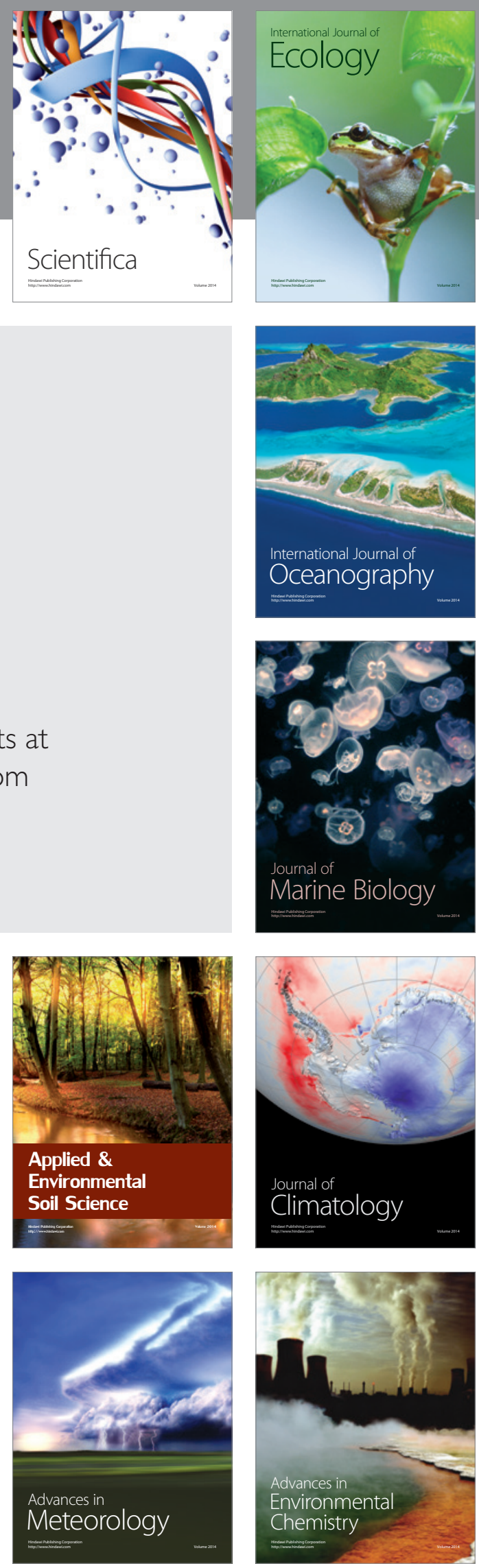